\title{
EXPLORING THE INTERCONNECTIONS BETWEEN HOUSING AND HEALTH: A REVIEW OF THE CANADIAN LITERATURE
}

by

Dara Vlajkovic, Honours BA, Health \& Society, York University, 2006

A Major Research Paper

presented to Ryerson University

in partial fulfillment of the requirements for the degree of

Master of Arts

in the Program of

Immigration and Settlement Studies

Toronto, Ontario, Canada, 2012

(C) Dara Vlajkovic, 2012 
I hereby declare that I am the sole author of this Major Research Paper. This is a true copy of the MRP, including any required final revisions, as accepted by my examiners.

I authorize Ryerson University to lend this paper to other institutions or individuals for the purpose of scholarly research.

I further authorize Ryerson University to reproduce this MRP by photocopying or by other means, in total or in part, at the request of other institutions or individuals for the purpose of scholarly research.

I understand that my MRP may be made electronically available to the public.

Dara Vlajkovic 


\title{
EXPLORING THE INTERCONNECTIONS BETWEEN HOUSING AND HEALTH: A REVIEW OF THE CANADIAN LITERATURE
}

\author{
Dara Vlajkovic \\ Masters of Arts 2012 \\ Immigration and Settlement Studies \\ Ryerson University
}

"Safe, affordable, and healthy housing is not only a basic necessity for human health and human life but also a means to reducing systemic health inequities and lowering associated long-term healthcare costs. A good home is critical to allow people to fully participate in the economic, social, and cultural lives of their community and their country" (Shapcott, 2010, p.15).

\begin{abstract}
This paper reports on the current state of knowledge on the association between housing and health concerning immigrants and refugees in Canada, based on an extensive review of the literature. The aim of this literature review is to provide a critical overview of the existing housing and health literature that focuses specifically on immigrant and refugee settlement experiences in Canada. The key objectives of this review are to critically review academic and non-academic research from the housing and health literature published within the last 10 years, to identify research needs and gaps, and to provide recommendations for future research.
\end{abstract}

Keywords: Canada; Immigrant and Refugee; Minority Health; Housing and Health; Social Determinants of Health 


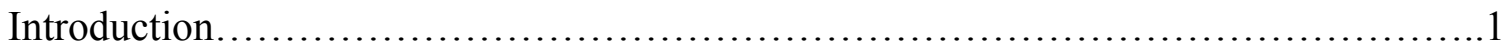

\section{SECTION ONE-Background}

A: Contextualizing Newcomers' Housing Challenges............................. 3

B: Housing Policy in Canada............................................... 5

C: Health Care and Health Policy in Canada.....................................9

D: Importance of Integrating Housing and Health Policies In Canada..............12

E: Definitions.......................................................... 13

SECTION TWO-Data Sources and Search Strategy

A: Peer Reviewed Journal Article...........................................15

B: The Grey Literature (Reports and Other Documents).......................16

C: Inclusion Criteria.................................................... 16

\section{SECTION THREE-Literature Review}

A: Poor Housing Conditions and Health........................................... 17

B: The Housing and Health Relationship ........................................ 18

C: Housing and Health Issues Among the Canadian Population........................21

D: Emerging Topics Identified From The Literature Review..........................25

D.1: Poor Housing Conditions and Immigrant and Refugee Health Status........27

D.2: Housing Conditions in Relation to Child Health Status.........................32

D.3: Homelessness and Health Status.........................................34

D.4: Hidden Homelessness and Health Status....................................37

SECTION FOUR-Findings From The Literature Review

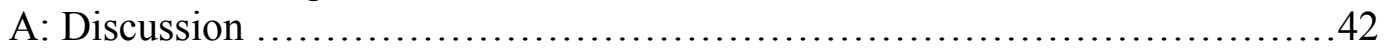

B: Conclusion......................................................... 43

C: Recommendations for Future Research................................44

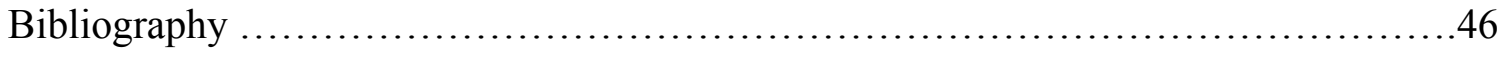




\section{Introduction:}

The notion of housing as a public health issue is not recent (Dunn, 2000, Krieger \& Higgins, 2002; Shaw, 2004). There is a body of research both nationally and internationally, demonstrating the relationships between poor living conditions and health. Even in the early 1800 s, public health practitioners in the United States and Europe recognized this relationship (e.g. 1830s cholera outbreak in New York City) (Kriegers \& Higgins, 2002, p.760) and recommended to city planners that in order to stop the spread of infectious diseases, housing conditions (e.g. overcrowding and maintenance) should be improved. In the middle of the $19^{\text {th }}$ century, a German physician named Rudolf Virchow (also known as the "Father of Modern Pathology") identified how societal policies determine health and emphasized the direct links between social conditions and health (Raphael, 2004). ${ }^{1}$

During the mid 1800s, political economist Friedrich Engels studied the health conditions of working class citizens in England. Engels contended that social class disparities in health were related to poor living and working conditions (Raphael, 2004) 2 . In the early 1900s, in Toronto's slums, outbreaks of disease led to the development of the country's first affordable housing projects (e.g. Spruce Court and Bain Co-op built in 1913) (Shapcott, 2004). In the 1930s, poor conditions in many communities spearheaded the development of large-scale government-managed public housing, beginning in the late 1940s. Canadian housing history over the past 100 years has demonstrated a cycle of

\footnotetext{
${ }^{1}$ Virchow's report (1848) on the typhus epidemic in Upper Silesia argued that "lack of democracy, feudalism, and unfair tax policies in the province were the primary determinants of the inhabitants' poor living conditions, inadequate diet, and poor hygiene that fuelled the epidemic" (Raphael, 2004, p.3). Virchow advised city officials that poorly maintained and crowded housing was associated with a greater risk of infectious disease transmission (Krieger \& Higgins, 2002).

2 Engels in his study, The Working Condition of Working Class in England (1845), describes the poor living and working conditions of working class people. As one of several examples, Engels demonstrated how profound differences in death rates in a suburb of Manchester were directly associated with quality of housing and quality of streets (Raphael, 2004). He recognized the mechanisms that led to disease and early death among working classes. Engels found that material conditions of life such as poverty, poor housing, clothing, diet, and lack of sanitation contributed to the high rates of infections and diseases among the poor (Raphael, 2004).
} 
growing concerns, which are eventually addressed to some degree by government responses (Shapcott, 2004).

The relationship between housing and health is long-standing. Despite such an obvious and close link between housing and health, social policies in Canada have been seldom interconnected. Housing impacts population health and other determinants of health, but this has not been recognized and applied in the policy-making process. Lack of access to affordable and quality housing is also a serious public policy issue in Canada. Newcomers have unique needs and circumstances that would affect health-oriented housing policy development. Many newcomers face chronic housing quality and affordability issues, as well as poverty, crowding and housing discrimination. Currently, Canada does not have a single national survey that combines both housing quality and population health. A national longitudinal survey that includes health, housing, and community metrics, within a single integrated design, is needed to generate reliable indicators of how changes in housing affect population health.

This paper reports on the current state of knowledge on the association between housing and health concerning immigrants and refugees in Canada, based on an extensive review of the literature. The aim of this literature review is to provide a critical overview of the existing housing and health literature that focuses specifically on immigrant and refugee settlement experiences in Canada. The key objectives of this review are to critically review academic and non-academic research from the housing and health literature published within the last 10 years, to identify research needs and gaps, and to provide recommendations for future research. 


\section{SECTION ONE-Background}

\section{A: Contextualizing Newcomers' Housing Challenges}

To contextualize the discussion, the following section will explore the various settlement issues immigrants and refugees experience in Canada. Canada is known as a major receiving country and in 2010, Canada admitted a record 280,636 permanent resident immigrants (CIC, 2010a, p.1). Of these, Ontario received 118,116 permanent resident immigrants, which accounted for 42.1 percent of the overall admissions to Canada. Approximately 78 percent $(92,181)$ of permanent residents in Ontario settled in the Toronto census metropolitan area (CMA) and 55.3 percent of these $(50,968)$ settled in the City of Toronto census division (CD) (CIC, 2010, p.1). In 2010, Ontario's permanent residents were: 58.8 percent $(69,491)$ in the Economic class; 24.8 percent $(29,333)$ in the Family class; 11.8 percent $(13,934)$ were Refugees; and 4.5 percent $(5,354)$ came from the "Other" immigration classes and categories (mainly public policy admissions) (CIC, 2010a, p.1).

The majority of settlement services are offered initially to support newcomers, but the process of settlement continues throughout the life of the newcomer. These services should be offered on a long-term basis throughout their years of adaptation (Omidvar \& Richmond, 2003). Settlement services are critical to immigrants' economic success and socio-political inclusion (Omidvar \& Richmond, 2003). Recent immigrants are generally poorer than earlier immigrants and their native-born Canadian counterparts, and the income gap between immigrants and other Canadians continues to grow (Picot \& Sweetman, 2005). Newcomers are often denied the opportunity to utilize their education and skills and to be remunerated based on their training and experience because of 
barriers in the licensing and accreditation process, employers' attitudes towards internationally gained skills and experience, and Canadian work experience requirements (Galabuzi \& Teelucksingh, 2005). Immigrants who are highly skilled and have foreign credentials are often employed in jobs they are overqualified for and work for low wage as a result. Consequently, the failure to recognize foreign credentials is contributing to precarious employment and poverty among immigrants in Canada.

The number of recent immigrants with family incomes below the low-income cutoff increased from 24.6 percent in 1980, to 31.3 percent in 1990, and 35.8 percent in 2000 (Picot, 2005 \& Sweetman, p.11). In Ontario, 2006 census data reveal that Asian and African-born recent immigrants have considerably poorer labour-market outcomes, whereas European-born immigrants' outcomes are more comparable to those born in Canada (Wachsmuth, 2008, p.5). Income is an important determinant of health and it influences access and quality of housing (Raphael, 2004). There is an indirect link between housing and health through the intermediary of income (Wachsmuth, 2008). Immigrants who lack access to affordable housing are more likely to be poor, and there is a strong link between poverty, income inequality and poor health outcomes (Wachsmuth, 2008). The first step towards successful integration for immigrants and refugees is finding a suitable place to live, in a good quality neighbourhood, and with adequate access to services. This is particularly important for some recent immigrants with limited financial resources (Murdie, 2003). The local housing market determines one's ability to access suitable housing at an equitable cost. Accessing affordable housing is often challenging for many because vacancy rates are low, rental costs are high, and wait lists for social housing are long (Murdie, 2003). Lack of access to affordable housing may 
jeopardize immigrants' prospect for integration, and children who grow up in poor quality housing often encounter educational and health difficulties (Wachsmuth, 2008).

Recent immigrants, especially renters, have a particularly high incidence of core housing need. Recent immigrant renter households in core housing need spend approximately half of their income on shelter (CMHC, 2004, p.6). Furthermore, two in five recent immigrant renters in Ontario pay more than 30 percent of their income on housing (Wachsmuth, 2008, p.6). In 2006, the core housing need for recent immigrants was 35 percent in "total" (e.g. both owned and rented), down from 36 percent in 2001 (CMHC, 2010, p.4). The core housing need of recent immigrant households was three times more than non-immigrant households in 2006 (CMHC, 2010). Furthermore, less than one-third of recent immigrants owned their own home in 2001 (CMHC, 2004, p.3). Murdie's (2003) study found that recent immigrants with low-income had difficulties accessing affordable housing, allocated a large amount of their income to housing, and consequently, had little money left over to cover other essentials such as healthy food, clothing, education, and transit. Thus, excessive spending on rent contributes to food and housing insecurity, malnutrition, use of food banks and poorer health outcomes (Raphael, 2004).

\section{B: Housing Policy in Canada}

The housing system in Canada consists of different tenures including homeownership (68 percent of households), private rental housing (25 percent of households), and social rental housing (around 5 percent of households) (CHRA, 2009). Starting in the 1950s, many social housing programs were funded by federal, provincial, and municipal governments, which built over 600,000 homes across Canada (CHRA, 
2009). Between the mid-1960s and mid-1980s, the federal government provided a wide range of housing programs addressing Aboriginal housing, neighbourhood improvement, housing rehabilitation, non-profit and cooperative housing (Terashima, 2005).

Since the 1970s, social and economic changes have significantly restructured the global economy, particularly the processes of production and investment (Bryant, 2009). Starting in the 1980s in Canada and other countries around the world, the Keynesian welfare state (KWS) ${ }^{3}$ has been significantly eroded and substituted by the neo-liberal state, which valorizes the private over the public sector (Man, 2004). There was an exaggerated anxiety over government deficits, which resulted in policies of "fiscal restraint" and rigorous cuts in social and health spending (Arat-Koc, 1999; Bryant, 2009). Many social support programs are continually being dismantled, and former statesubsidized programs are being downsized, privatized, or completely abolished.

According to neo-liberalism ${ }^{4}$, "the notion that all citizens have a right to a basic standard of living and that society is responsible for the well-being of its individual members, are no longer valid" (Arat-Koc, 1999, p.34). Neo-liberalism places a greater emphasis on self-reliance and the "atomized market player" (Arat-Koc, 1999). The good citizen is one that works longer and harder to become more self-reliant. If a person is unable to find a job because of tight labour market conditions or cannot afford to go to school, the economic and social consequences are placed on the individual. Thus, the extreme liberal view of self-reliance puts the onus on the individual and shifts the responsibility and

\footnotetext{
3 The modern welfare state is commonly referred to as the Keynesian welfare state (KWS) and is named after economist John Maynard Keynes. The welfare state refers to "state intervention in the provision of supports and services that include education, social services such as employment insurance and training, public pension, social assistance, and health care. In addition to providing citizens with various kinds of security, the creation of the welfare state also served as a vehicle to promote resource distribution and promote class harmony" (Bryant, 2009, 233).

4 Neo-liberalism has been defined as "the belief that the marketplace should be the arbiter of the creation and distribution of various resources" (Bryant, 2009, p.19). Neoliberalism has led to a considerable reduction in government support of key social determinants of health such as income, housing, food security, among others.
} 
blame away from the state and market.

As a result of economic restructuring and the retrenchment of the Welfare State in the mid-1980s, the federal government began to cut back funding for new affordable housing in Ontario. After the 1990s, no new affordable housing was built in Ontario (Shapcott, 2010). In 1996, negotiations began between the federal government and many provinces and territories to download the responsibility of the provision of social housing (Terashima, 2005). Federal government devolution agreements phased out federal subsidies and delegated the responsibility of social housing to the provinces and territories. Federal housing subsidies were only allocated to low-income households under this agreement (Terashima, 2005). In 1998, the Ontario government announced plans to download the majority of its housing programs to municipalities (Shapcott, 2010).

During the 1990s, there was a sizeable increase in homelessness and other considerable signs of emerging housing insecurity, which set in motion a number of short-term initiatives by the federal government (Shapcott, 2010). The first initiative was the National Homelessness Initiative in 1999, followed by the federal-provincialterritorial Affordable Housing Initiative (AHI) of 2001 (Shapcott, 2010). In 2001, under the AHI, the federal government allocated $\$ 680$ million to provincial and territorial housing authorities (CMHC, 2011, p.137). In the 2003 budget, an additional $\$ 320$ million was provided over a five-year period to increase access to affordable housing for low-income households (CMHC, 2011, p.137). In 2008, the federal government committed $\$ 1.9$ billion over five-years to support low-income Canadians, those at risk of homelessness, and the homeless (CMHC, 2011, p.138). By July 2011, all three levels of 
government announced a $\$ 1.4$ billion joint investment under a new Investment in Affordable Housing 2011-2014 Framework Agreement (CMHC, 2011, p.139).

Canada has one of the most market-oriented housing systems in the world, such that approximately 80 percent of Canadians are served by market-based housing (e.g. individual home ownership and private rental housing) (CMHC, 2012; Fuller-Thomson et al., 2000). In addition, Canada is one of very few countries globally without a national housing plan (Shapcott, 2010). Over the past decade, government policy has depended on private markets to deliver suitable and affordable home ownership or rental housing, despite the fact that many Canadian households are excluded from private housing markets (Shapcott, 2010). On average, homeowners have twice the income, have a lower rate of core housing need, and receive the largest share of federal financial support (through federal home sale capital gains tax subsidies) (Shapcott, 2010). This clearly demonstrates that Canadian housing policy is biased and supports homeowners over renters. When housing access is allocated on a market basis rather than on the basis of need, individuals with low-income are confined to the bottom end of the housing market. (Fuller-Thomson et al., 2000). This segment of the housing market may be less costly, but is at the expense of poor quality housing and poor neighbourhoods. (Fuller-Thomson et al., 2000). Barbara Hall, Chief Commissioner of the Ontario Human Rights Commission, declared that Access to affordable housing is a "basic human right" (Shapcott, 2010). Having access to adequate, affordable and suitable housing is a fundamental prerequisite for good health, and it impacts all aspects of one's life. However, the integration of both housing and health jointly in policy development continues to be overlooked by policy makers. 


\section{C: Health Care and Health Policy in Canada}

Canada has a publicly funded and privately run health care system, known as 'medicare' ${ }^{5}$. The Canadian health care system consists of ten provincial and three territorial health insurance plans and is based on five founding principals (care must be universal, portable, comprehensive, accessible, and publicly administered) (Irvine, Ferguson, \& Cacket, 2005). The system is also characterized by local control, doctor autonomy and consumer choice. In 1944, the Saskatchewan government, led by Tommy Douglas, was the first province to introduce universal hospital insurance. The 1972 federal Medical Care Act marked the first time that all provinces and territories offered comprehensive hospital and medical insurance to Canadian residents (Irvine, Ferguson, \& Cacket, 2005). The Canadian Health Act received Royal Assent in 1984 and the Act defined the five founding principals of medicare.

A commonly held definition of 'health' is that of the World Health Organization (WHO): "a state of complete physical, mental, and social well-being and not merely the absence of disease or infirmity" (WHO, 1948). Health policy includes both health care and other health-related public policies and is concerned with improving and maintaining population health (Bryant, 2009). The Canadian government plays a direct role in organizing health care and resource distribution of health care services to the population. The administration and delivery of health care is decentralized and health care is primarily financed by tax dollars. Federalism ${ }^{6}$ has shaped the organization, allocation of

\footnotetext{
5 Medicare in Canada should not be confused with Medicare in the United States which is only accessible to Americans ages 65 and older, younger people with disabilities, and people with end stage renal disease.

6 Federalism refers to "the division of political power and authority between a central or national government and regional governments. In Canada, these regional governments are the provincial and territorial governments" (Bryant, 2009, p.7).
} 
responsibility, and delivery of health care between the federal and provincial governments (Bryant, 2009). The federal government finances some of the costs of provincial health care programs through cash transfers and controls some of the regulations for health service provision by the provinces and territories (Bryant, 2009).

From the 1960 s to 1980 s, the federal government played a considerable role in funding health care services. Subsequently in the 1980s and 1990s, the federal government reduced much of its revenue transfers to the provinces and territories while still attempting to retain control over health care (Bryant, 2009). During this period, the government implemented market-oriented policies in order to substitute the welfare state with a neo-liberal regime, which has greatly impacted the relationship between the state and society. The roles of the various levels of government in health care and healthrelated policy have changed dramatically through funding cuts to health care. Private sector involvement in Canadian health care is one of the largest among developed nations. The justification for reducing health and social spending by Canadian governments is on the basis of concerns about the sustainability of medicare and to ensure competitiveness in the global market (Bryant, 2009).

The federal government's reduction in revenue transfers to the provinces has increased private sector involvement in the financing and delivery of health services (Bryant, 2009). The issue of wait times for health care has prompted discussion between the provincial governments to increase the involvement of the private sector in health care. However, using public funds to finance private health services infringes on the principals of the Canada Health Act. As a cost cutting measure, provinces have delisted drugs that were previously covered by provincial drug formularies and implemented user 
fees for a number of services that were formerly insured. Most Canadians do not have access to supplementary care such as vision, dentistry, mobility aids, and pharmaceuticals. Supplementary benefits are not routinely covered by a provincial health care plan and are typically covered by private insurance as an employee benefit.

The selection policies of Citizenship and Immigration Canada are restrictive such that immigrants with serious medical conditions are not admitted to Canada. These policies have been implemented to supposedly protect the health and safety of Canadians and to reduce the burden on Canada's health and social services system. In Ontario, landed immigrants and returning Canadians are subject to a three-month waiting period for OHIP health insurance coverage. Immigrants are required to pass a strict medical examination prior to being accepted into Canada, and for this reason are unlikely to strain the health care system. Many doctors in Ontario are advocating for the elimination of the three-month wait so that all patients may access care when they need it. The healthy immigrant effect suggests that most new immigrants to Canada are generally healthier than the average Canadian-born. After living in the country for more than ten years, immigrants lose this health advantage and their health becomes comparable to that of their native-born counterparts (Fuller-Thomson, Noack, \& George, 2011; Hyman, 2004). Most immigrants come in good health and they may only require health services on some unexpected occasions. Thus, the three-month waiting period for health coverage must be eliminated to ensure the health of our new immigrants is protected.

On June 30, 2012, bill C-31 came into effect, which significantly changed access to health care for refugees in Canada under the Interim Federal Health Program (IFHP). The IFHP provides limited and temporary coverage of health-care benefits to: protected 
persons, including resettled refugees; refugee claimants; and other groups that are not eligible for provincial or territorial health insurance. The major changes to the IFHP include ending coverage for most pharmacy benefits, and all vision, dental and other supplemental benefits. Refugees may only access health care in emergency situations or if their condition is considered a threat to public health. Changes to the IFHP will leave vulnerable persons such as refugees without health coverage for medications such as insulin for diabetes or inhalers for asthma. Without access to essential medications and health services, this can lead to serious and long lasting medical complications.

\section{D: Importance of Integrating Housing and Health Policies in Canada}

Where you live, in terms of your postal code, your neighbourhood and the quality of housing, greatly impacts population health. Evidence has shown the many ways in which our homes and neighbourhoods may affect health outcomes. The quality of housing and how well the housing is maintained play a critical role in the incidence of asthma and other chronic respiratory symptoms. By providing healthier and more affordable housing in neighbourhoods that are accessible to vital services (i.e. individuals with chronic conditions having access to needed care), this will help reduce the overall burden on our health-care system and improve the quality of life of Canadians. The national affordable-housing crisis is costly to individuals, communities, and our health care system. Lack of access to high quality and affordable housing is preventing Canadians from meeting basic needs such as nutrition and health care, as well as other essentials that promote good health. High rent costs create a situation where purchasing medication(s) on a fixed income becomes a luxury, which means health conditions are left untreated and often become chronic. Chronic diseases are among the most common 
health problems facing Canadians and the most costly to our health care system. By providing families with quality housing in safe neighbourhoods, this can reduce stress, promote mental health and other health benefits. There is a need for a more coordinated development of housing that is closer to health care services, public transportation, jobs, a variety of grocery stores, as well as green spaces and recreation centres. It is imperative that housing and health policies are integrated, as they are fundamentally interconnected. This can only be achieved if governments recognize the role of housing in health and vice versa. Governments must also adopt a social determinants ${ }^{7}$ approach to health as a component of the policy-making process.

\section{E: Definitions}

For the purpose of this paper the following terms will be used: (1) healthy housing, (2) precarious housing (or hidden homelessness), (3) immigrants and recent immigrants, (4) refugees, and (5) core housing need (adequate, suitable and affordable). The next few paragraphs will provide a working definition of each of these terms.

The World Health Organization (WHO) has developed a broad definition of 'healthy housing' which includes four dimensions: "the house structure, the home social environment, the neighbourhood and the community. Healthy housing is regarded as a means of protecting inhabitants' health from a variety of risks in the built and natural environment - physical, chemical, biological and psycho-social" (WHO, 2011, p.10). 'Precarious housing' refers to housing that is not affordable, temporary accommodation

\footnotetext{
7 The 'social determinants of health' can be defined as:

The economic and social conditions that influence the health of individuals, communities, and jurisdictions as a whole. Determinants of health are about the quantity and quality of a variety of resources that a society makes available to its members. These resources include - but are not limited to - conditions of childhood, income, availability of food, housing, employment and working conditions, and health and social services. (Raphael, 2004, p.1)
} 
in shelters, couch surfing (no fixed address), overcrowding, or is unfit for habitation (Gopikrishna, 2012; Shapcott, 2010).

'Immigrant' refers to an individual who has gained legal status to reside in Canada, such as permanent residents, visitors and students. Some are 'recent immigrants' who have been living in Canada within the last ten years while others have resided in Canada for a longer period of time (over ten years). 'Refugees ${ }^{, 8}$ also referred to as "Protected Persons in Canada", are permanent residents in the refugee category who had their refugee claims accepted and who applied for and were granted permanent resident status in Canada (CIC, 2010b). Refugees include government-assisted refugees, privately sponsored refugees and refugees landed in Canada ${ }^{9}$.

A household is in 'core housing need" "if it does not meet one or more of the adequacy, suitability or affordability standards and it would have to spend 30 percent or more of its before-tax income to pay the median rent of alternative local market housing that meets all three standards" (CMHC, 2004, p.4). 'Adequate' refers to housing that is not in need of major repairs (CMHC, 2010). 'Suitable' refers to housing that has enough bedrooms to accommodate the size and make-up of residents in the household, according to National Occupancy Standard (NOS) requirements (CMHC, 2010). 'Affordable'

\footnotetext{
8 According to the 1951 United Nations Convention Relating to the Status of Refugees, a refugee is "a person residing outside his or her country of nationality, owing to a well-founded fear of being persecuted for reasons of race, religion, nationality, membership of a particular social group or political opinion, is unable to, or owing to such fear, is unwilling to avail himself/herself of the protection of that country" (UNHCR, n.d. para.3).

9

9 Refugees landed in Canada "are permanent residents in the refugee category who have had their refugee claims accepted and who subsequently applied for and were granted permanent resident status in Canada. With the introduction of the Immigration and Refugee Protection Act (IRPA), this group is referred to as -"Protected persons in Canada" (CIC, 2010b, p.120).

Privately sponsored refugees "are permanent residents in the refugee category who are selected for resettlement in the Convention Refugees Abroad Class, the source country class or the country of asylum class, and who are privately sponsored by organizations, individuals or groups of individuals" (CIC, 2010b, p.120).

Government-assisted refugees "are permanent residents in the refugee category who are selected abroad for resettlement to Canada as Convention refugees under the IRPA or as members of the Convention Refugees Abroad Class, and who receive resettlement assistance from the federal government" (CIC, 2010b, p.120).
} 
refers to housing that costs less than 30 percent of before-tax household income (CMHC, 2010).

\section{SECTION TWO-Data Sources and Search Strategy}

\section{A: Peer Reviewed Journal Articles}

The findings of this paper stem from a review of the literature on housing and health among immigrants and refugees, which can be found across multiple academic disciplines. This review drew on information and insight primarily from published scholarly sources such as academic journals, reports, and books, using a combination of formal and informal search methods. The formal search method used to search for academic articles was carried out through various indexes including: Medline (PubMed), Healthstar, Academic Search Primer, Proquest Research Library, Sociological Abstracts, and Social Science Abstract. The search for relevant literature was also undertaken using Google Scholar. The search was limited to peer reviewed articles that were published in the last 10 years in English. Furthermore, the reference list of various studies and reports on housing and health was reviewed to help identify additional sources. Keywords were identified through several article abstracts and from reviewing the housing and health literature. Key search terms included: (i) immigrant or refugee or newcomers; (ii) health or disease or mental health or physical health or chronic or acute conditions (iii) minority health; (iv) housing or hous* or housing conditions or environmental conditions or unsatisfactory living conditions or precarious housing or hidden homelessness or couch surfing or overcrowding or physical and/or chemical exposure or inadequate housing or unsuitable housing or living arrangements or housing deprivation. Using the key term (v) Canada resulted in a modest number of studies. Fewer studies look at the association 
between housing and health among immigrants and refugees in Canada, so the search was expanded to other Western nations. The Boolean operators 'AND' and 'OR' were used to broaden (e.g. using OR) or narrow (e.g. using AND) the search results. While 'NOT' was used to eliminate a word or a combination of words from the search results. Asterisks were also used to truncate search terms (e.g. hous*).

\section{B: The Grey Literature (Reports and Other Documents)}

An informal search was carried out via the Internet search engine Google using various key terms. Reports and other documents were screened using the same inclusion criteria as the peer reviewed electronic sources and using the same key terms. From the Internet search, reputable reports were retrieved from websites such as the Wellesley Institute, Metropolis web sites, Citizenship and Immigration Canada, Statistics Canada, and the Canadian Mortgage and Housing Corporation. In addition, a search was carried out through the Homeless Hub, which is a research and information centre that focuses on homelessness issues in Canada.

\section{C: Inclusion Criteria}

The retrieved sources were screened for relevance. The search focused on studies and other grey literature that examined the relationship between housing and health specifically concerning immigrants and refugees in Canada. However, some studies that looked at housing and health among the Canadian population were also included. Studies from other Western nations that examined housing and health among immigrants or refugees were also included. The criteria used for inclusion of materials from various indexes was on the basis of using only scholarly and peer-reviewed publications, limiting the search by subject terms (e.g. housing, immigrants, health aspects and health 
outcomes), country, content type (e.g. journal articles, reports, books and other scholarly sources), publication date (e.g. last 10 years), and language (e.g. English). Potential abstracts were screened for relevance and once the article was identified as relevant, it was read in full and included in the final review.

A critical analysis of all sources was carried out by carefully assessing the type of study, research design, sample size and potential for biases. Studies were critically reviewed, assessed and synthesized until saturation was reached, gaps were identified and future research avenues were noted.

\section{SECTION THREE-Literature Review}

\section{A: Poor Housing Conditions and Health}

Substandard living and housing conditions have a huge impact on residential health. Features of inadequate housing which have long been attributed to the spread of infectious disease, such as lack of clean drinking water, ineffective waste disposal, presence of insects and vermin, and absence of hot water for washing (Krieger \& Higgins, 2002). Some of the major health threats found in dwellings which affect residential health include poor indoor air quality, home safety, noise, humidity and mould growth, indoor temperatures, radon, lead, asbestos, volatile organic compounds (VOC), lack of hygiene and sanitation equipment, and crowding (Bonnefoy, 2007; Kriegers \& Higgins, 2002). More recent epidemiological studies have found links between inadequate housing and increased risk of developing chronic illness. Housing that is damp, cold, and mouldy is associated with asthma and other chronic respiratory symptoms (Krieger \& Higgins, 2002). Cross-sectional epidemiological studies have 
found associations between damp and mouldy housing and chronic headaches, fever, nausea, vomiting and sore throats (Krieger \& Higgins, 2002).

Inadequate housing increases the risk of injuries from unprotected windows, slippery floors, exposed heating sources and poorly designed stairs. Furthermore, substandard housing has been linked to poor mental health. Housing deprivation in early childhood has been found to contribute to moderate or severe ill health in adulthood (Krieger \& Higgins, 2002; Wachsmuth, 2008). Neighbourhood and community characteristics have been found to impact health, education, employment, as well as other quality of life outcomes (Carter \& Polevychok, 2004). A number of studies in the United States, Europe, and a growing body of literature in Canada, provide evidence of the negative effects of living in deprived neighbourhoods on individuals' socio-economic mobility, health status, and criminal activity (Hou \& Picot, 2003).

\section{B: The Housing and Health Relationship}

Housing is an important determinant of health and there is extensive research that demonstrates that poor housing conditions play a considerable role in health outcomes (Bonnefoy, 2007; Bryant, 2003; Carter \& Polevychok 2004; Dunn, 2000; Dunn \& Hayes, 2000; Fuller-Thomson, Hulchanski, \& Hwang, 2000; Moloughney, 2004; Raphael, 2004; Shapcott, 2010). The body of literature on the housing and health relationship demonstrates that certain characteristics and exposures in residential dwellings have considerable health effects, but there is a lack of a general theory of the mechanisms by which housing impacts health (Fuller-Thomson et al., 2000). Many studies have found a correlation between housing and health outcomes, but attempts to prove poor housing actually causes ill health have often failed (Carter \& Polevychok, 2004; Jacobs \& Baeder, 
2009; Moloughney, 2004). The causal relationship between housing factors and health outcomes can be hidden or attributed to a number of confounding variables (e.g. occupation, education, income, wealth, and social and neighbourhood environment).

The housing and health relationship is measured between housing-related independent variables and health-related dependent variables. Housing-related variables include, but are not limited to: specific chemical and biological exposures, housing design and structure, indoor air quality, overcrowding, housing tenure, affordability and satisfaction, and quality of neighbourhood. Health status is commonly measured via selfreported health questionnaires. Many studies on the housing and health relationship rely on self-reported health status rather than measurement of health outcomes (identifying the context, measuring health status prior to carrying out an intervention, measuring the intervention, re-measuring health status afterwards, and then relating the change to the intervention). Relying on self-reported health status can be problematic because some participants may feel a social need to under-report certain conditions, and participants in focus groups may feel uncomfortable sharing sensitive health-related information in a group setting, which may impact estimates of disease prevalence.

There is a gap in research with respect to the relationships and pathways between housing and health status. Research on the association between housing and health seldomly considers the existence of a two-way relationship: housing impacts health and health impacts housing (Fuller-Thomson et al., 2000). Housing may have both direct and indirect effects on health. According to Fuller-Thomson et al. (2000), a relationship between a housing factor and health effect may be described in the following ways: (i) the housing factor is the cause of the health effect; (ii) the housing factor contributes to 
the health effect but does not directly cause the health effect; (iii) a confounding factor causes the housing factor and health effect, but the housing factor alone does not cause the health effect; (iv) poor health status caused the housing factor to be present; (v) and the relationship was found due to bias or chance.

The strongest evidence available linking housing and health effects are for a number of biological, chemical and physical exposures. Research, both nationally and internationally, has found that these types of exposures are strong mechanisms for causing poor health (Moloughney, 2004). Studies that have examined lead, radon, asbestos, allergens, and environmental tobacco smoke exposures provide the strongest evidence for causal relationships between poor housing and ill health (Bryant, 2004; Moloughney, 2004). Moreover, several physical environmental factors (e.g. home safety, smoke detectors and protection from extremes of cold and heat) have also demonstrated strong evidence of causal relationships. Studies have examined psychosocial mechanisms (e.g. building type, floor level of apartment buildings, overcrowding and housing tenure), but these studies only provide possible findings on housing conditions and health effects. The results of these studies are often weak or inconclusive (Bryant, 2004; Moloughney, 2004). Studies on neighbourhood effects on health show strong associations, but it is hard to differentiate economic and social factors from housingspecific factors (Moloughney, 2004). Thus, understanding the correlations between housing and health have proven difficult because of weak research designs, flawed strategies for statistical analysis, and conflicting results (Moloughney, 2004). 


\section{C: Housing and Health Issues Among the Canadian Population}

In Canada, housing issues have not been a priority on the agenda of many health researchers, despite a growing body of literature demonstrating their effect on health outcomes (Bryant, 2003). The bulk of the research on housing and health has focused on the Canadian population as a whole, without identifying visible minority population subgroups (Bryant, 2004; Dunn, 2000, Dunn, 2002; Dunn, 2003; Dunn et al., 2006; FullerThomson et al., 2000, Frankish, Hwang \& Quantz, 2005; Hwang, Martin, Tolomiczenko, \& Hulchanski, 2003; Shapcott, 2004; Shapcott, 2010). Aside from Aboriginal peoples, the majority of the Canadian population is comprised of Canadian citizens, permanent residents, and non-citizen temporary residents. A total of eight studies, seven reports and two books were retrieved on housing and health among the Canadian population for this literature review.

Research on housing and health has focused on, and identified findings in, four important areas (Dunn, 2000). First, homeless people have poor health outcomes and have inadequate access to health care. Second, poor housing conditions are associated with poor physical and mental health outcomes. Third, stresses associated with inadequate housing can impact health status. Fourth, people who are unhealthy are often marginalized in the housing market and subjected to substandard housing conditions.

Dunn et al.'s (2006) Needs, Gaps and Opportunities Assessment (NGOA) uncovered four emerging themes in the housing and health field that participants in the stakeholder consultations identified as priorities. The themes identified in four priority areas were: (1) economic aspects of housing and health, (2) housing and health for vulnerable groups across the lifespan, (3) housing, social integration and income/ethnic mix, and (4) 
interplay between physical hazards and socio-economic aspects of housing. The participants from the consultation workshops recommended that further high-priority research is required on housing and health conditions of immigrants and ethnic minorities.

There is well-established research on the health effects of physical, chemical and biological hazards in the home, but research is needed around the intersection of these exposures with socio-economic status (Dunn et al., 2006). It is recognized that physical and mental health is linked to the physical and built environment, although little is known about what aspects of the built environment actually impact either physical or mental health (Bond et al., 2012). Several studies have explored the association between mental illness and the built environment and neighbourhoods (Evans, 2003; Guite, Clark, \& Ackrill, 2006; Weich et al., 2002). The various aspects of the built environment and neighbourhood that are associated with poor mental health include: housing type (e.g. living in high-rise buildings, social isolation and lack of space for recreational activities), housing quality (e.g. crowding, poor structural quality, maintenance, amenities, and physical hazards), and neighbourhood quality (e.g. noise, fear of crime, percentage of unemployment, and lack of green space) (Evans, 2003; Guite, Clark, \& Ackrill, 2006). Moreover, several studies have shown that people who live in poorer neighbourhoods experience a variety of adverse health outcomes in comparison to those in more affluent neighbourhoods (Moloughney, 2004).

Seven dimensions of housing have been identified that potentially contribute to social inequalities and, either directly or indirectly, to health consequences. The housing dimensions include: physical hazards, physical design, social dimensions of housing, 
psychological, political (e.g. housing quality, availability and affordability is influenced by public policy), financial dimensions, and housing location (Dunn, 2003). The aforementioned dimensions may combine with other types of social disadvantages to negatively affect health. Dunn and Hayes (2000) found that an individual's housing experience, characteristics of the domestic environment, total monthly rent, percentage of income paid toward rent, and having a sense of control or the security of tenure, are all important factors that influence mental health and general health status.

Hwang, Martin, Tolomiczenko, and Hulchanski (2003) examined the housing conditions and health status of rooming house residents in Toronto. The study found that participants aged 35 years and older reported poor health status. Chronic conditions were commonly reported among the roomers (e.g. back problems, migraine headaches, arthritis, high blood pressure, sinusitis, asthma, urinary incontinence, and chronic bronchitis). Participants who reported the poorest health were more likely to reside in rooming houses in the poorest physical condition

In Canada, it is estimated that between 150,000 and 300,000 persons are homeless and 1.5 million households are in core housing need (i.e. homes that are unaffordable or in need of major repairs) (CHRA, 2009, p.2). Three million households pay more than 30 percent of their income towards their rent and 900,000 Canadians are categorized as the hidden homeless (Shapcott, 2010, p.4). According to census data, an estimated 705,165 Canadians are living in overcrowded housing mainly due to high rents (Shapcott, 2010, p.4). Statistical and research reports on housing issues are generally published by the federal government, statistics Canada, the national statistical agency, and the Canada Mortgage and Housing Corporation (CMHC), but there is no national figure on the exact 
number of homeless people (Shapcott, 2010).

Federal statistics capture the number of households that exceed occupancy standards, but this figure overlooks the hidden homeless (Shapcott, 2010). It is difficult to measure 'hidden homelessness' because as the name implies, people are 'homeless' and it is 'hidden'. The hidden homeless are not resorting to the shelter system, although they are at risk of ending up in a shelter or on the streets. Disclosure of overcrowding and couch surfing to landlords or government officials is on a volunteer basis, and many tenants fear eviction if they disclose such information. It is likely that the number of Canadians living in overcrowded households or couch surfing is much higher than the aforementioned numbers reported (Shapcott, 2010).

Many studies have examined homelessness and the impact it has on the health of the Canadian population. Studies have found correlations between homelessness and poor health, but the causal pathways connecting homelessness and poor health are complex. Research has demonstrated associations between homelessness and poor health outcomes such as mental illness, chronic conditions (e.g. respiratory disease, arthritis, high blood pressure, asthma, epilepsy and diabetes), infectious diseases (e.g. HIV and TB), and substance abuse related illness and injuries (Bryant, 2003; Dunn, 2000; Frankish, Hwang, \& Quantz, 2005; Hwang, 2001; Shapcott, 2010; Springer, Roswell, \& Lum, 2006). Frankish, Hwang, and Quantz (2005) in their review of the literature on homelessness and health status, concluded that there is a strong correlation between homelessness and poor physical and mental health. Poor health status may also increase the risk of homelessness. Homelessness is the outcome of a combination of factors at the individual level (e.g. lack of education, job skills and income, substance abuse, and mental illness) and societal 
level (e.g. poverty, labour market conditions, racism, and discrimination) (Anucha 2006;

Frankish, Hwang, \& Quantz, 2005; Greenberg \& Martinez-Reyes, 2009).

For many Canadians, lack of access to affordable and safe housing has led to homelessness. In Ontario, 124,032 people on wait lists for social housing (Grant \& Munro, 2012, p.355). There is not enough low-rent housing available to meet the demand. Moreover, evidence has shown that there is an overrepresentation of people with severe mental health issues among the homeless population (Zine, 2009). Approximately 33 percent of men in hostels and 75 percent of women have severe mental health issues (Zine, 2009). Homeless people with severe mental health-related issues experience more obstacles to employment, are often in poorer physical health, remain homeless longer, and have more encounters with the legal system, in comparison to the rest of the homeless population (Zine, 2009).

A report by Anucha, Smylie, Mitchell, \& Omorodion (2007) examined the homeless population in Winsor-Essex County to understand the reasons behind their exists and returns to homelessness. Some of the reasons reported for becoming homeless included trouble with family and the law, physical abuse, substance abuse, and mental health-related issues. The study also found that participants reported many health issues, both physical and mental, including frostbite, respiratory illnesses, susceptibility to hepatitis $\mathrm{C}$, depression or being suicidal, poor nutrition, hunger, sexually transmitted infections and HIV.

\section{D: Emerging Topics Identified From The Literature Review}

The discussion at this juncture will start with the current state of knowledge of housing and health research concerning immigrants and refugees in Canada. The paper 
will then discuss the literature on housing and health among immigrants and refugees under four topics: (D.1) Poor Housing Conditions and Immigrant and Refugee Health Status, (D.2) Housing Conditions in Relation to Child Health Status, (D.3) Homelessness and Health Status, and (D.4) Hidden Homelessness and Health Status. In total, four types of studies were retrieved from reviewing the literature: (1) Empirical qualitative research such as focus groups and interviews with adult immigrants and refugees, (2) Crosssectional studies, (3) Longitudinal survey analyses, and (4) Literature reviews.

Canadian research on housing and health among immigrants and refugees is growing, but there is a need for an integrated body of housing and health research. To date, there have been limited peer-reviewed studies that have assessed the effects of poor housing environments and health conditions among immigrants and refugees in Canada. The bulk of the research on this topic consists of reports. Research on immigrants and refugee housing in Canada has focused on three metropolitan areas, where the majority of newcomers settle. These cities include Toronto/GTA, Montreal and Vancouver, but research is growing in cities such as Calgary, Halifax, and Winnipeg.

There are many sources of funding for various research projects which include, but are not limited to: Citizenship and Immigration Canada, the Homelessness Partnering Strategy through Human Resources and Skills Development Canada, Canada Mortgage and Housing Corporation, Social Housing Services Corporation, Toronto Public Health, Ontario Ministry of Municipal Affairs and Housing, Toronto Community Housing, Metropolis Project, United Way, Poverty Reduction Coalition, City of Calgary, Social Development Canada, Social Sciences and Humanities Research Council of Canada, and Canadian Institutes of Health Research. Reports that have been subsequently revised and 
published in a refereed journal were included. A total of 14 reports on housing and health among immigrants and refugees in Canada were retrieved. The remainder of the sources was retrieved from book chapters.

Research on housing and health among minorities in other Western nations is much more extensive than in Canada. From the US research on housing and health concerning minorities, nine studies and one report were retrieved, and three studies were retrieved from the United Kingdom for this literature review. Studies conducted in the US generally focus on the following aspects of housing and impact on health status: physical characteristics (e.g. housing design and indoor air quality), biological (e.g. dampness and mould, dust mites, cockroaches and other vermin), and chemical or physical exposures (lead and asbestos). There are many US studies on poor housing conditions and asthma among minority children, but Canadian research in this area is lacking and less understood. Research studies on housing and health among foreign-born residents in the United States generally use the term minority, which refers to all race/ethnicity categories excluding Anglo-American (e.g. African American, Asian American, and Latin American). In Canada, studies use immigration status as a variable (e.g. protected person, permanent resident, and temporary resident).

\section{D.1: Poor Housing Conditions and Immigrant and Refugee Health Status}

Overall health and well-being is dependent on one's ability to access and afford good quality housing. Research findings on the association between poor housing conditions and health have been instrumental in policy and regulation development in areas including sanitation, carbon monoxide testing, lead poisoning, and improving construction and fire safety within homes (Shapcott, 2010). However, policies that 
reduce access to affordable quality housing and the availability of financial resources, greatly impact other determinants of health including food security, early life, education and recreation. Ultimately, this leads to social exclusion and adverse affects on health status (Bryant, 2003). A report by Carter and Polevychok (2004) draws the link between housing policy and broader social and economic policy, such as education, labour market and health. The authors argue that by improving housing policy, this will facilitate the development of new affordable and suitable housing, and make the integration process easier for immigrants in Canada. In addition, better housing policy would allow for more funding towards social assistance, employment insurance, health and education.

A report by Carter, Polevychok, Friesen, \& Osborne (2008) examined the housing circumstances of recently arrived refugees in Winnipeg over a two-year period. The research findings highlight the difficulties many recently arrived refugees encounter in their first year and the changes that occur by the second year. During the first year of this study, refugee households were much larger than in the second year. Over the two-year period, there continued to be a growing dissatisfaction with conditions of their units and work orders took long to be fulfilled. A broad range of reasons were reported: four participants felt that the cold in their units made them sick in the winter; six indicated rashes or breathing problems from dirty carpeting or dusty air; peeling pain and crumbling walls were concerns for some; two units had bedbugs which impacted their quality of sleep; and some felt that mental health was affected because their households were too dark, small or lacked windows. This report was subsequently published.

Preston et al.'s (2011) report found that refugees and asylum seekers in Toronto reported that poorly maintained and unhealthy housing were common problems. More 
than half of asylum seekers live in overcrowded and unhealthy housing. Around two thirds of sponsored refugees and half of all asylum seekers mentioned that unhealthy conditions including mould, bedbugs and other vermin, and inadequate ventilation were problems with their current housing. Half of all sponsored refugees and 40 percent of asylum seekers reported poor maintenance, whereas a lower proportion of non-refugee immigrants reported these problems. Participants in every focus group expressed concerns about the quality of air and the risk of developing illnesses such as asthma, as well as the effect of living in basements on their own health and well-being of their families.

A report by the United Way examined high-rise private and non-profit rental housing, and the nature and extent of poverty in Toronto's inner suburban neighbourhoods among recent newcomers to Canada, older immigrants, and Canadianborn tenants (MacDonnell et al., 2011). Both types of high-rise buildings were found to be poorly maintained, work orders took long to complete, residents were living with vermin and other pests, many homes were found to be poorly ventilated with the presence of mould, and heating and cooling systems were defective. However, tenants living in non-profit buildings reported more issues in common areas (e.g. higher levels of elevator breakdown), more pests and vermin issues, and higher levels of crime and social disorder. These housing issues were found to have a negative impact on the physical and mental health of residents, particularly vulnerable populations such as children, seniors and individuals living with a pre-existing health condition.

Tanasescu et al.'s (2009) report provides key findings concerning the housing challenges faced by newcomers to Calgary. In Calgary, 42 percent of immigrant renters 
and 24 percent of immigrant homeowners are in need of affordable housing (Tanasescu et al., 2009, p.iii). A significant number of participants reported that they resided in housing that required repairs. Around 34 percent reported their housing to be in need of repair and nine percent were in need of major repair (Tanasescu et al., 2009, p.iii). Six interviewees who rented a basement suite and paid cheaper rent reported mould, a lack of windows, rodent infestation, and lack of light (Tanasescu et al., 2009, p.iv). The reported healthrelated impacts were: high stress levels (most common), weight loss, depression, high blood pressure, and constant illness (e.g. reccurring cold). The health-related impacts were believed to be consequences of high stress levels, unsafe and unhealthy housing conditions.

A US study by Pollack, Griffin, and Lynch (2010) investigated whether housing affordability is associated with a number of health outcomes while controlling for perceptions of neighbourhood quality. The study found that 48.4 percent of respondents reported difficulty paying housing costs (Pollack, Griffin, \& Lynch, p. 519). In addition, respondents who live in unaffordable housing were more likely to report cost-related prescription drug and healthcare non-adherence, fair or poor self-reported health status, food insecurity, and certain chronic conditions (e.g. high blood pressure and arthritis). The strongest association was found between housing unaffordability and cost-related outcomes, thus "supporting the mechanism that unaffordable housing is associated with financial trade-offs and reduced discretionary spending on health-related expenses" (Pollack, Griffin, \& Lynch, 2010, p.519). The association between unaffordable housing and self-rated health was stronger among renters than homeowners and the authors argue that this may be related to the emotional stress of insecure housing. 
Early et al. (2006) conducted a study on housing conditions of Latino farm worker families in North Carolina, to identify which housing features impact their health. Data were collected from two participatory community-based research projects, La Familia and Casa y Campo. Most of the farm worker families reside in mobile homes and many are located in close proximity to agricultural fields. The majority of households were found to be too small to accommodate family size and crowding was common. The Latino farm worker families felt that crowding was harmful to their quality of life. Furthermore, numerous farm worker households lack washers and dryers and vacuum cleaners. The authors argue that not having access to a washer and dryer in the home is problematic because it helps protect workers from pesticide exposure.

A 30-year retrospective study conducted in the US by Jacobs, Wilson, Dixon, Smith, and Evens (2009), examined the relationship between housing and population health. Data were compiled and combined from two nationally representative longitudinal surveys of the US population and its housing, namely the National Health and Nutrition Examination Survey and the American Housing Survey. The changes in housing found over a 30 year period included: construction type, proportion of rental versus home ownership, age, density, size, moisture, pests, broken windows, ventilation and air conditioning, and water leaks. The changes found in health measures included: asthma, respiratory illness, obesity and diabetes, and lead poisoning, among others. The results suggest that ecological trends in childhood lead poisoning are associated with housing age, water leaks and ventilation, and that asthma is associated with ventilation, windows and age (Jacobs, Wilson, Dixon, Smith, \& Evens, 2009). 


\section{D.2: Housing Conditions in Relation to Child Health Status}

In Canada, research on housing and health among immigrant and refugee children is almost non-existent. The link between poor living conditions and respiratory illness, such as asthma and chronic obstructive pulmonary disease among minority children, has been well documented in international studies (Shapcott, 2010). Studies have found that housing deprivation during childhood leads to moderate or severe health effects in adulthood (Bryant, 2003). Many health risks can be traced back to homes, schools, and other indoor environments, and children are particularly vulnerable to adverse exposures since they spend 80-90 percent of their time indoor (Breysse et al., 2004, p.1583). In the United States, housing inequity continues to be a major issue with regards to exposures to environmental hazards and poor health outcomes, particularly in poor and minority communities (Litt et al., 2009). National studies in the US report that children of immigrants tend to reside in lower income and less educated households, their parents often lack proficiency in English, and they are exposed in excess to chemical and physical hazards such as indoor air pollutants, inadequate housing, and overcrowding (Litt et al., 2009).

In the US, asthma incidence, prevalence, and hospitalization rates are much higher among the poor and even greater among low-income minority children (Rauh, Landrigan, \& Claudio, 2008). An estimated 300,000 children and 700,000 adults in New York City have been diagnosed with asthma at one point in their lifetime (Rauh, Landrigan, \& Claudio, 2008, p.279). In addition, in the US, approximately 60 percent of Hispanics and 50 percent of African Americans, in comparison to 33 percent of their Caucasian counterparts, reside in neighbourhoods that do not meet two or more of the 
national ambient air quality standards (Rauh, Landrigan, \& Claudio, 2008). Housing quality, especially poor air quality, has been linked to high rates of asthma in low-income urban communities (Hunninghake, Weiss, \& Celedon, 2006; Rauh, Landrigan, \& Claudio, 2008). Studies have found associations between asthma and chronic exposures to allergens in the indoor environment including mould, pets, mice and rats, cockroaches, and dust mites (Breysse et al., 2004).

The most common neurotoxicants found in homes are lead (e.g. lead paint dust), pesticides, and ETS (environmental tobacco smoke) (Breysse et al., 2004, p.1584). Exposure to lead affects brain and neurodevelopment processes. According to the CDC (Centre for Disease Control), 17 percent of children from low-income families in the US have elevated blood lead levels (e.g. > $10 \mathrm{ug} / \mathrm{dL}$ ) (Breysse et al., 2004, p.1584). In the immigrant population in Massachusetts, the prevalence of blood lead levels among children is twice as high as in US born children (Eamranond \& Hu, 2008, p.47). It is well known that exposure to tobacco smoke, both first-hand and second-hand, is harmful. Tobacco smoke exposure during and after pregnancy has been linked to premature births, low birth weight, poor growth of infants, and disruptive child behavior (Breysse et al., 2004, p.1585). Moreover, several studies have found that exposure to cholinesteraseinhibiting pesticides such as organophosphates and carbamates (used to control vermin and pests), is a serious health concern.

A US study by Litt et al. (2009) examined housing conditions among recently immigrated Mexican families. The study found that hazardous environmental conditions were common in the participants' homes. The majority of participants had low socioeconomic status and almost all had household incomes below the average household 
income in Colorado. Conditions such as dampness and mould (44 percent), pests ( 28 percent), minimal to no ventilation (26 percent) and indoor smoking (16 percent) were all found to be associated with asthma and atopic diseases, especially among children in the households under study (Litt et al., 2010, p.623). More than 25 percent of homes were found to be overcrowded, and three percent were severely crowded (Litt et al., 2010, p.620). The study relied on self-report health information, which could have impacted estimates of asthma and atopic disease prevalence. Blood lead samples were collected from participants, but the authors never discussed what they found from collecting the blood samples.

\section{D.3: Homelessness and Health Status}

Homelessness in Canada is a troubling nation-wide crisis and there is a greater representation of recent immigrants among the hidden homeless than the visibly homeless (Enns, 2005). Newcomers to Canada are increasingly experiencing challenges finding and maintaining affordable and suitable housing (Tanasescu et al., 2009). Immigrants and refugees are at an increased risk of becoming homeless in comparison to their Canadianborn counterparts. Refugee claimants are an immigrant sub-group that are at greater risk of becoming homeless because the refugee-determination process can include periods of precarious status (e.g. upon arrival and if the claim fails) (Kissoon, 2010b). Without legal status, refugee claimants are unable to access services such as social housing, social assistance, food banks, work permits, some emergency shelter services, and provincial health insurance (Kissoon, 2010b).

Several other factors put refugee claimants at risk of homelessness, including lack of social networks, cultural familiarity, and proficiency in the official languages 
(Kissoon, 2010b). Other studies have shown that immigrants and refugees are more likely to become homeless as a result of financial reasons and lack of access to affordable housing (Wachsmuth, 2008). Recent immigrants and refugees usually seek cheaper accommodations due to low-income, share rents with family or friends and reside in crowded households to avoid becoming homeless (Fiedler, Schuurman, \& Hyndman, 2006a; Hiebert, D'Addario, \& Sherrell, 2005). According to the Longitudinal Survey of Immigrants to Canada (LSIC), 14 percent of immigrants indicated that they had no family income, and 50 percent of immigrants with a family income reported it to be less than $\$ 1600$ per month (Statistics Canada, 2005, p.22). The average monthly rent for a twobedroom unit in Toronto is $\$ 1000, \$ 900$ in Vancouver and Ottawa, and $\$ 500$ in Montreal (Statistics Canada, 2005, p.22).

An emerging body of research literature has examined barriers immigrants and refugees encounter in Canadian housing markets (Carter \& Osborne, 2009; Murdie, 2003; Pruegger \& Tanasescu, 2007; Sherrell, D’Addario, \& Hiebert, 2007; Teixeira, 2010; Teixeira, 2009; Teixeira, 2008). Newcomers often experience discrimination in rental housing, especially among racialized Canadians, which increases the risk of homelessness and hidden homelessness (Pruegger \& Tanasescu, 2007). Discrimination in rental housing frequently occurs as a result of: landlords refusing social assistance recipients, rent advance and credit history, request for a guarantor, proof of employment, references from prior landlords, having to pay a financial premium (e.g. six months worth of rent or more) to be selected as a tenant, and some landlords have a no children policy (Pruegger \& Tanasescu, 2007; Gopikrishna, 2012). Research has shown that social networks are critical for many immigrants in the settlement process as they may help with 
tasks including finding a home, a job or school, accessing health and social services, joining community groups, and overcoming barriers in the rental housing market (e.g. by sharing accommodations) (Statistics Canada, 2005). At entry, most immigrants reported having either a friend and/or relative in Canada (87 percent) (Statistics Canada, 2005, p.19).

A number of studies examine homelessness among the immigrant population in Canada, but without referencing health outcomes (Anucha, 2006; Enns, 2005; Fiedler, Hiebert, D'Addario, \& Sherrell, 2009; Fiedler, Schuurman, \& Hyndman, 2006a; Fiedler, Hyndman, \& Schuurman, 2006b; Kissoon, 2010a; Paradis, Novac, Sarty, \& Hulchanski, 2010; Paradis, Novac, Sarty, \& Hulchanski, 2009; Preston et al., 2009). A report by Hiebert, D'Addario, and Sherrell (2009) on absolute and relative homelessness among immigrants, refugees and refugee claimants in Vancouver, found that the most cited reasons for homelessness are physical or emotional abuse, family issues and mental health issues. Anucha's (2006) report adopted a community dialogue approach to study homelessness and hidden homelessness among immigrants and refugees in Windsor and Essex County. The study found that a number of participants had difficulties in coping with their poor housing conditions. The issues reported were inadequate ventilation, no heat, crowding, rodents and pests, structural issues, and noisy neighbours. Several participants reported that their poor housing conditions adversely impacted their children's health. A participant explained that her children were frequently sick because of the poor condition of her subsidized unit (e.g. old carpets, rats and insect nests on the wall). 
A report by Kilbride, Webber, Wong, and Amaral (2006) examined homelessness, hidden homelessness, immigrants and social capital in Toronto, Peel Region, and Hamilton. The study found that a number of interviewees reported that they suffered from severe health conditions such as arthritis, asthma, high blood pressure, diabetes, joint and body aches, depression, and cancer, among others. Findings from the key informant focus groups revealed that many newcomers had low income and/or received social assistance and could not access affordable private market housing. Key informant focus group members also reported that language barriers, lack of Canadian education and work experience, and the accreditation process, made it difficult for newcomers to find employment and put them at risk of homelessness. A Toronto based report on housing and homelessness in the Latin American and Muslim communities examined the social, economic, and political conditions that contribute to the marginalization and disenfranchisement of these community members. The study found that 55 percent of the respondents felt that they were at risk of becoming homeless, 42 percent reported that the main reason for being at risk was that their rent was too expensive. Another major factor mentioned was not being able to pay rent on time (Zine, 2009). In addition, 19 percent of the respondents stated that they have not had a permanent home in the last five years, and 22 percent were presently without a permanent home. Moreover, 34 percent of respondents felt that their living conditions were inadequate (e.g. improper heating, ventilation, cockroaches and mice).

\section{D.4: Hidden Homelessness and Health Status}

It is well recognized in the housing and health literature that living in an overcrowded environment is generally unhealthy (Early et al., 2006; Evans, 2003; Fuller- 
Thomson et al., 2000; Goux \& Maurin, 2005; Krieger \& Higgins, 2002; Litt et al., 2009; Solari \& Mare, 2012). Studies have examined high levels of household crowding ${ }^{10}$ and the impact on psychological and physical health, but there is little consensus on whether and how the effects actually occur (Fuller-Thomson, et al., 2000). People who live in close proximity to one another are at a greater risk of spreading infectious diseases (Evans, 2003; Krieger and Higgins, 2002). Research on the hidden homeless has been given much less attention than the visibility homeless. The issue of hidden homelessness in the immigrant community has received increased academic attention in recent years, particularly with respect to overcrowding (Anucha 2006; Gopikrishna, 2012; Greenberg \& Martinez-Reyes, 2009; Hann, 2010, Hiebert, D'Addario, \& Sherrell, 2009; Preston et al., 2011; Pruegger \& Tanasescu, 2007; Shapcott, 2010). However, couch surfing has been given much less research attention compared to overcrowding.

Many LSIC immigrants indicated that they lived in two (21 percent), three (24 percent), or four ( 22 percent) person households, and 12 percent reported living in a household of six or more people (Statistics Canada, 2005, p.24). Almost one in four recent immigrants ( 23 percent) indicated that they lived in a household that had more than one person per room. In addition, 40 percent of refugees reported living in a crowded dwelling (Statistics Canada, 2005, p.26).

Newcomers are more inclined to access informal networks (e.g. family members, friends and cultural or faith communities) rather than formal housing supports to avoid the shame associated with being a 'burden on the system' and the inaccessibility of housing supports (Greenberg \& Martinez-Reyes, 2009). During the early stages of

10 According to the Census definition, crowding is when a household has more than one person per room (e.g. in the living room, bedroom(s), kitchen or basement) (Statistics Canada, 2005, p.25). 
settlement, informal networks are important as they can protect newcomers from absolute homelessness. However, these networks are less likely to have full and reliable information compared to organizations that specifically provide housing support as part of their mandate (Greenberg \& Martinez-Reyes, 2009). Scholars argue that social networks and ethnic enclaves play a vital role in providing supports to newcomers, but this can often lead to dependency and prevent integration (Greenberg \& Martinez-Reyes, 2009).

A body of research has examined the impact of crowding on health and education outcomes in the field of sociology, psychology and medicine (Curtis, Corman, Noonan, \& Reichman, 2010; Goux \& Maurin, 2005; Solari \& Mare, 2012). Goux and Maurin (2005) conducted a study in France on overcrowding and the effect it has on children's performance in school, using sex composition of the siblings as instrumental variables. The study found a correlation between housing conditions (e.g. overcrowding) and academic performance (e.g. poor academic performance). Children who live in a household with a larger family size performed worse in school than children from smaller families, and this was attributed to overcrowding. The likelihood of being held back a grade in school increased considerably based on the number of people per room in the household (Goux \& Maurin, 2005). In a US study, Solari \& Mare (2012) examined household crowding on children's academic achievement, behaviour, and well-being, using national longitudinal data from the Panel Study of Income Dynamics' Child Development Supplement and Los Angeles Family and Neighbourhood Survey. Solari and Mare (2012) found that living in an overcrowded household is negatively associated with several aspects of child well being (e.g. cognitive, behavioural, and health 
outcomes), despite controlling for various dimensions of socioeconomic status.

Hiebert, D'Addario, and Sherrell (2009) found in their report that a common housing outcome for many refugee claimants is overcrowding. Refugee claimants are residing in neighbourhoods that have lower rental rates, at the cost of housing quality, higher crime rates, drug abuse and prostitution. Many of the participants reported that they coped by sharing rents and by living in crowded households, as well as in poor quality housing. Hann (2010) argues that there are both positive and negative aspects to crowding. The positive aspects of living in a crowded household are that it allows residents to pool resources and have access to schools, neighbourhoods, businesses and investment opportunities. This may increase economic, employment, social and residential mobility. In contrast, the negative aspects of living overcrowdedly were demonstrated in a group of studies which found a correlation between household crowding and poor mental health, lower life satisfaction, child performance and labour productivity outcomes, as well as an increased risk of contracting tuberculosis, shigellosis, and pneumococcal infections (Hann, 2010).

Evans, Lapore, and Allen (2000) investigated cross-cultural variability in tolerance for crowding among four ethnic groups (e.g. Asian American, Latin American, African American, and Anglo-American). The authors examined the relations of culture and density on psychological distress. The study found that Mexican Americans and Vietnamese Americans perceive crowding differently in comparison to African Americans and Anglo-Americans. The authors argue that members' collectivist cultural groups often view their home as less crowded. However, the study could not confirm that psychological distress in relation to crowding differs by culture (Evans et al., 2000). 
Gopikrishna's (2012) chapter examined hidden homelessness among newcomers in the Greater Toronto area by drawing on practical experience of front line workers and anecdotal information. Hidden homelessness, particularly crowding, was discussed as adversely impacting children and youth because there is often not enough space to complete their homework or concentrate on their studies. Social tensions between families residing in the same confined space and anecdotes about depression (and other mental health problems) associated with sharing living space with multiple people were discussed (Gopikrishna, 2012). Newcomers who reside in housing situations of hidden homelessness often have limited or fixed incomes, and an increase in rent means less money is available to allocate towards food, medications and other living expenses.

Preston et al.'s (2011) report examined conditions of overcrowding as one of many aspects of housing, specifically among refugees, asylum seekers, and immigrants in Toronto. Participants reported that they were often forced to share accommodations that were unsafe and with limited privacy in order to offset high housing costs that they could not pay. Overcrowding was also found to occur when participants had concerns over neighbourhood safety. Households that were overcrowded were found to create conditions for intra-familial conflict, abuse, and general lack of privacy. Thus, overcrowding was found to have a negative impact on the mental health of many newcomers.

In Kilbride, Webber, Wong, and Amaral's (2006) report, a hidden homeless woman and newcomer from Peel shared her experience of depression. She explained, "I feel too weak. I cannot sleep at night and I am taking sleeping pills. I have problem concentrating. I often feel like crying and I have pain in my body" (p.43). A hidden 
homeless woman from Toronto explained her experience of living in an overcrowded household with 11 other people. The women explains:

Since last September, I got severe rheumatism, which made it too painful to walk. While waiting for the specialist, I was asked to take a kind of medicine and the side effect gave me a heart attack and made me have blood in my stool. The worst thing is that it makes me need to go to washroom many times. It's very inconvenient for me because I am sharing a washroom with 11 other people, and the washroom is downstairs. In the winter, the room is cold and I couldn't control myself and I wet my bed. (Kilbride et al., 2006, p.43).

Another hidden homeless female from Toronto who resides with eight other family members in a tiny two-bedroom apartment describes her concerns about living under such conditions:

It's noisy, there is absolutely no privacy whatsoever; one never gets enough sleep due to the noise and the number of people around everywhere. But it is better than staying in a shelter or even worse on the streets. So I am very lucky.

(Kilbride et al., 2006, p.62)

Although living conditions were found to be poor for many interviewees, for the most part, they felt grateful that at least they were not living in a shelter.

\section{SECTION FOUR-Findings from The Literature Review}

\section{A: Discussion}

Housing is a basic human right and is an important area of settlement for newcomers to Canada. Having access to affordable housing plays a critical role in the relationship to other determinants of health. The construction of new social housing for low and moderate-income renters has not been available since 1993. In Canada, a national housing plan is required to tackle the housing crisis and homelessness disasters, and to ensure that Canadians have access to affordable and quality housing. Canada relies 
heavily on the private sector to provide housing, so a shift towards increasing the supply

of affordable rental housing in the public and non-profit sectors is needed to help low and moderate-income renters. Non-conventional, illegal or secondary rental market housing (e.g. basement apartments) must be regulated to protect tenants. The restoration and renewal of existing social housing buildings is imperative to promote the health and wellbeing of tenants.

\section{B: Conclusion}

This literature review identified six major findings: (1) the absence of a comprehensive and fully-funded national housing plan, one that acknowledges that housing impacts population health and other determinants of health, (2) a paucity of peerreviewed Canadian research on housing and health among immigrants and refugees, (3) most reports exist on housing and health among immigrants and refugees in Canada and these studies only touched on health outcomes, (4) a need to integrate housing and health research in Canada, (5) a need to combine both housing and health policies to improve housing conditions and population health, and (6) a general theory of the mechanisms by which housing impacts health is required, although it may be challenging due to a number of potential confounding variables.

There are some limitations associated with this literature review. The sources retrieved on housing and health among immigrants and refugees is not an extensive list and the sources are primarily Canadian reports. The search strategy for electronic sources was limited to six databases, and due to time constraints, a number of studies and reports may have been overlooked. Moreover, certain housing, health and immigrant related key search words might have been missed in the search for sources. 
This literature review offers readers such as students, academics and practitioners an overview of the immigrant and refugee housing and health experience from a Canadian perspective. In terms of the practical relevance, research connecting housing conditions and health status may influence the modification of municipal bylaws, building codes, and environmental health regulations.

\section{C: Recommendations for Future Research}

This literature review has emphasized a strong consensus that more research is necessary in the area of immigrant housing and health in Canada. Ongoing research on housing and immigrant health and well-being in Canada is critical to our understanding of this population and to address their diverse health needs. There are reports that examine the housing and health of immigrants in Canada, but research is not as extensive as in other Western nations.

Research is needed to examine health status (both chronic and acute) in relation to postal code among different immigrant groups. Research has focused on the associations between housing and mental health outcomes among immigrants, but more research is needed on newcomer sub-populations. More long-term longitudinal and quasiexperimental studies are required on housing as a socio-economic determinant of health among immigrants and refugees. These studies may provide stronger evidence of an association between housing and health. The population sample has to be large enough to capture the heterogeneity of immigrant groups and the diverse neighbourhoods in which they settle. More quantitative studies (both longitudinal and cross-sectional) on housing and health among the immigrant population are required. Documented evidence from the immigrant population is necessary rather than anecdotal information of their experience 
of poor housing conditions and its adverse impact on their health.

Canadian-based research on the relationship between housing quality and child development, and between housing and seniors' well-being is needed. Increased attention needs to be paid to examine the ways in which adequate and suitable housing may improve the health and well-being of immigrant groups. Ethnographic studies on a local level are needed to track the lived experiences of diverse Canadian immigrant groups. Research is lacking in the housing and health experience of immigrants and refugees with disabilities. Persons with special needs are overrepresented among the poor and are more likely to have housing-related challenges. A gender-based analysis that examines the associations between the housing and health of immigrants and refugees would be particularly valuable. Very little research has been conducted on visibly homeless immigrants and refugees and the impact it has on their health. An increased understanding and awareness of newcomer homelessness and hidden homelessness is required. 


\section{Bibliography}

Anucha, U., Smylie, L., Mitchell, C., \& Omorodion, F. (2007). Exits and Returns: An Exploratory Longitudinal Study of Homeless People in Windsor-Essex County. Ottawa: Canada Mortgage and Housing Corporation.

Anucha, U. (2006). A Community Dialogue on Homelessness among Immigrants and Refugees in Windsor and Essex County. Toronto: Final Report, CERIS Research Grant 2004-2005.

Arat-Koc, S. (1999). "Neo-Liberalism, State Restructuring and Immigration: Changes in Canadian Policies in the 1990s". Journal of Canadian Studies, 34(2), 31-56.

Bond, L., Kearns, A., Mason, P., Tannahill, C., Egan, M., \& Whitely, E. (2012). "Exploring The Relationships Between Housing, Neighbourhoods and Mental Well-being for Residents of Deprived Areas.” BMC Public Health, 12 (48), 1-14.

Bonnefoy, X. (2007). "Inadequate Housing and Health: An Overview”. Int. J. Environment and Pollution, 30 (3/4), 411-429.

Breysse, P., Farr, N., Galke, W., Lanphear, B., Morley, R., \& Bergofsky, L. (2004). “The Relationship between Housing and Health: Children at Risk". Environmental Health Perspectives, 112(15), 1583-1588.

Bryant, T. (2003). "The Current State of Housing in Canada as a Social Determinant of Health." Policy Options, 24(3), 52-56.

Bryant, T. (2004). Housing and Health. In D. Raphael (ed.). Social Determinants of Health: Canadian Perspectives (pp. 217-234). Toronto: Canadian Scholars Press Inc.

Bryant, T. (2009). An Introduction to Health Policy. Toronto: Canadian Scholars' Press Inc.

Carter, T., \& Osborne, J. (2009). "Housing and Neighbourhood Challenges of Refugee Resettlement in Declining Inner City Neighbourhoods: A Winnipeg Case Study." Journal of Immigrant and Refugee Studies, 7, 308-327.

Carter, T., \& Polevychok, C. (2004, December). Housing is Good Social Policy. Ottawa: Canadian Policy Research Networks Inc.

Carter, T., Polevychok, C., Friesen, A., \& Osborne, J. (2008, July). The Housing Circumstances Of Recently Arrived Refugees: The Winnipeg Experience. Edmonton: Prairie Metropolis Centre. 
CIC. (2010a). Ontario Immigration Key Facts Preliminary 2010 Data. Ottawa: Citizenship and Immigration Canada.

CIC. (2010b). Canada Facts and Figures 2009: Immigration overview, Permanent and Temporary residents. Ottawa: Research and Evaluation Branch, Citizenship and Immigration Canada.

CHRA. (2009). An Affordable Housing Policy for Canada. Ottawa: Canadian Housing and Renewal Association.

CMHC. (2004). 2001 Census Housing Series: Issue 7 Revised-Immigrant Households. Socio-economic Series 04-042. Ottawa: Canada Mortgage and Housing Corporation.

CMHC. (2010). 2006 Census Housing Series Issue: 7-The Housing Conditions of Immigrant Households. Socio-economic Series 10-016. Ottawa: Canadian Mortgage and Housing Corporation.

CMHC. (2011). 2011 Canadian Housing Observer. Ottawa: Canada Mortgage and Housing Corporation

CMHC. (2012). Government of Canada's Support for Housing. Retrieved August 17, 2012 from http://www.cmhc-schl.gc.ca/en/corp/nero/jufa/jufa_010.cfm

Curtis, M.A., Corman, H., Noonan, K., \& Reichman, N.E. (2010). "Effects of Child Health on Housing in The Urban U.S." Social Science \& Medicine 71, 2049-2056.

Dunn, J. (2000). "Housing and Health Inequalities: Review and Prospects for Research." Housing Studies, 15(3), 341-366.

Dunn, J. (2002). A Population Health Approach to Housing: A Framework for Research. Ottawa: Canada Mortgage and Housing Corporation.

Dunn, J. (2003). Housing as a Socio-Economic Determinant of Health: Assessing Research Needs. Research Bulletin \#15. Toronto, Ontario: Centre for Urban and Community Studies, University of Toronto.

Dunn, R, \& Hayes, V. (2000). "Social Inequality, Population Health and Housing in Two Vancouver Neighbourhoods." Social Science and Medicine, 51(4), 73-97.

Dunn, J., Hayes, M., Hulchanski, D.J., Hwang, S.W., \& Potvin, L. (2006). "Housing as a Socio-Economic Determinant of Health Findings of a National Needs, Gaps and Opportunities Assessment”. Canadian Journal of Public Health, 97 (3), S11-S15.

Eamranond, P.P., \& Hu, H. (2008). "Environmental and Occupational Exposures in Immigrant Health". Environmental Health Insights, 1, 45-50 
Early, J., Davis, S.W., Quandt, S.A., Rao, P., Snively, B.W., \& Arcury1, T.A. (2006). "Housing Characteristics of Farm Worker Families in North Carolina." Journal of Immigrant and Minority Health, 8(2), 173-184.

Enns, R. (2005). "Immigrant Households and Homelessness.” Canadian Issues, Spring, 127- 130 .

Evans, G.W. (2003). "The Built Environment and Mental Health.” Journal of Urban Health, 80(4), 536-555.

Evans, G.W., Lepore, S.J., \& Allen, K.M. (2000). “Cross-Cultural Differences in Tolerance for Crowding: Fact or Fiction?" Journal of Personality and Social Psychology, 79 (2), 204-210.

Fiedler, R., Schuurman, N., \& Hyndman, J. (2006a). "Hidden homelessness: An Indicator- based Approach for Examining the Geographies of Recent Immigrants At-risk of Homelessness in Greater Vancouver." Cities, 23(3), 205-216.

Fiedler, R., Hyndman, J., \& Schuurman, N. (2006b). Locating Spatially Concentrated Risk of Homelessness amongst Recent Immigrants in Greater Vancouver: A GISbased Approach. Vancouver: Research on Immigration and Integration in the Metropolis, RIIM Working Paper Series No. 06-15.

Frankish, C.J., Hwang, S.W., \& Quantz, D. (2005). "Homelessness and Health in Canada: Research Lessons and Priorities." Canadian Journal of Public Health, 96, S23-S29.

Fuller-Thomson, E., Hulchanski, J. D., \& Hwang, S. (2000). The Housing/Health Relationship: What do we know? Reviews on Environmental Health, 15(1-2), 109-134.

Fuller-Thomson, E., Noack, A.M., George, U. (2011). Health Decline Among Recent Immigrants to Canada: Findings From a Nationally-Representative Longitudinal Survey, Canadian Journal of Public Health, 102(4), 273-280.

Galabuzi, G., \& Teelucksingh, C. (2005). Working Precariously: The Impact of Race and Immigrants Status on Employment Opportunities and Outcomes in Canada. Toronto: Canadian Race Relations Foundation.

Gopikrishna, S. (2012). Hidden Homelessness in Greater Toronto Area's Newcomer Communities: Signs, Symptoms, and Solutions. In H. Bauder (ed.). Immigration and Settlement: Challenges, Experiences, and Opportunities (pp. 217-225). Toronto: Scholar's Press.

Goux, D., \& Maurin, E. (2005). "The Effect of Overcrowded Housing on Children's Performance at School”. Journal of Public Economics 89, 797 - 819. 
Grant , J.G., \& Munro, T. (2012). Housing Policy. In A. Westhues \& B. Wharf (eds.), Canadian Social Policy: Issues and Perspectives $5^{\text {th }}$ Edition (pp.355-370). Waterloo: Wilfrid Laurier University Press.

Greenberg, T., \& Martinez-Reyes, E. (2009, Fall). Hidden: Newcomer Experiences of Homelessness at Fred Victor and The Learning Enrichment Foundation. Toronto: Fred Victor and The Learning Enrichment Foundation.

Guite, H.F., Clark, C., \& Ackrill, G, (2006). "The impact of the physical and urban Environment on Mental Well-being." Public Health, 120(12), 1117-1126.

Hann, M. (2010, Fall). "The Residential Crowding of Immigrants to Canada". Canadian Issues/Thèmes Canadiens (Newcomer's Experiences of Housing and Homelessness in Canada). Montréal: Association for Canadian Studies, 16-20.

Hiebert, D., D’Addario, S., \& Sherrell, K. (2005). The Profile of Absolute and Relative Homelessness Among Immigrants, Refugees, and Refugee Claimants in the GVRD: Final Report. Vancouver: MOSAIC.

Hiebert, D., D’Addario, S., \& Sherrell, K. (2009). “Taking Care of their Own? Or Falling Between the Cracks? Absolute and Relative Homelessness Among Immigrants, Refugees, and Refugee Claimants in Vancouver." Chapter 5.2 in Hulchanski, J.D. et al., (eds.), Finding Home: Policy Options for Addressing Homelessness in Canada. Toronto: Cities Centre, University of Toronto.

Hou, F., \& Picot, G. (2003). Visible Minority Neighbourhood Enclaves and Labour Market Outcomes of Immigrants. Statistics Canada.

Hunninghake, G.M., Weiss, S.T., \& Celedon, J.C. (2006). "Asthma in Hispanics." American Journal of Respiratory and Critical Care Medicine, 173, 143-163.

Hwang, S. (2001). "Homelessness and Health." Canadian Medical Association Journal, 164(2), 229-233.

Hwang, S.W., Martin, R.E., Tolomiczenko, G. S., \& Hulchanski, J.D. (2003). "The Relationship Between Housing Conditions and Health Status of Rooming House Residents in Toronto." Canadian Journal of Public Health, 94(6), 436-440.

Hyman I. (2004). Setting the stage: Reviewing the current knowledge on the health of Canadian immigrants. What is the evidence and where are the gaps? Canadian Journal of Public Health, 9(3), 14-18.

Irvine, B., Ferguson, S., \& Cacket, B. (2005). Background Briefing: The Canadian Health Care System. Civitas. United Kingdom: The Institute for the Study of Civil Society. 
Jacobs, D.E, \& Baeder, A. (January, 2009). Housing Interventions and Health: A Review of the Evidence. United States: National Centre for Healthy Living.

Jacobs, D.E., Wilson, J., Dixon, S.L., Smith, J., \& Evens, A. (2009). “The Relationship of Housing and Population Health: A 30-Year Retrospective Analysis". Environmental Health Perspective, 117(4), 597-604.

Kissoon, P. (2010a, Fall). “An Uncertain Home: Refugee Protection, Illegal Immigration Status, and their Effects on Migrants' Housing Stability in Vancouver and Toronto." Canadian Issues/Thèmes Canadiens (Newcomer's Experiences of Housing and Homelessness in Canada). Montréal: Association for Canadian Studies, 8-15.

Kissoon, P. (2010b). (Dis) Advantages of Illegality: The Refugee Claimant Trajectories and Housing Experiences of Non-Status Migrants in Vancouver and Toronto. Vancouver: Metropolis British Columbia, Working Paper Series, No. 10-11.

Kilbride, K.M., Webber, S.M., Wong, C., \& Amaral, N. (2006). Plug Them in and Turn Them on: Homelessness, Immigrants, and Social Capital. Toronto: Report submitted to the Housing and Homelessness Branch of the Department of Human Resources and Social Development Canada.

Krieger, J., \& Higgins, D. (2002). "Housing and Health: Time Again for Public Health Action." American Journal of Public Health, (92), 758-768.

Litt, J., Goss, C., Diao, L., Allshouse, A., Diaz-Castillo, S., Bardwell, R., Hendrikson, E, Miller, S., \& DiGuiseppi, C. (2010). "Housing Environments and Child Health Conditions Among Recent Mexican Immigrant Families: A Population-Based Study." Journal of Minority Health, 12(5), 617-625.

MacDonnell, S., Robinson, J., Mikadze, V., \& McDonough, L., \& Meisner, A. (2011). Poverty by Postal Code 2: Vertical Poverty. Toronto: United Way Toronto.

Man, G. (2004). "Gender, Work and Migration: Deskilling Chinese Immigrant Women in Canada”. Women's Studies International Forum, 27, 135 - 148.

Moloughney, B. (2004, June). Housing and Population Health: The State of Current Research. Canadian Institute for Health Information \& Canadian Mortgage and Housing Corporation.

Murdie, R.A. (2003). “Housing Affordability and Toronto’s Rental Market: Perspectives from the Housing Careers of Jamaican, Polish and Somali Newcomers". Housing, Theory and Society, 20, 183-196. 
Murdie, R., \& Logan, J. (2011), Precarious Housing \& Hidden Homelessness Among Refugees, Asylum Seekers, and Immigrants: Bibliography and Review of Canadian Literature from 2005 to 2010. CERIS Working Paper No. 84.

Omidvar, R, \& Richmond, T. (2003, January). Immigrant Settlement and Social Inclusion in Canada. Toronto: The Laidlaw Foundation.

Paradis, E., Novac, S., Sarty, M., \& Hulchanski, J.D. (2009). "Better off in a Shelter? A Year of Homelessness \& Housing Among Status Immigrant, Non-Status Migrant, and Canadian- Born Families." Chapter 4.2 in Hulchanski, J.D. et al., (eds.), Finding Home: Policy Options for Addressing Homelessness in Canada. Toronto: Cities Centre, University of Toronto.

Paradis, E., Novac, S., Sarty, M., \& Hulchanski, J.D. (2010, Fall). “Homelessness and Housing Among Status Immigrant, Non-Status Migrant, and Canadian-Born Families in Toronto." Canadian Issues/Thèmes Canadiens (Newcomer's Experiences of Housing and Homelessness in Canada). Montréal: Association for Canadian Studies, 36-39.

Picot, G, \& Sweetman, A. (2005). The Deteriorating Economic Welfare of Canadian Immigrants and Possible Causes: Update. Statistics Canada.

Pollack, C., Griffin, B., \& Lynch, J. (2010). "Housing Affordability and Health Among Homeowners and Renters". American Journal of Preventive Medicine, 39(6), 515521.

Preston, V., Murdie, R., Wedlock, J., Agrawal, S., Anucha, U., D’Addario, S., Kwak, M.J., Logan, J., \& Murnaghan, A.M. (2009). "Immigrants and Homelessness - At Risk in Canada's Outer Suburbs.” The Canadian Geographer, 53(3), 288-304.

Preston, V, Murdie, R., D’Addario, S., Sibanda, P., Murnaghan, A., Logan, J., \& Hae Ahn, M. (2011). Precarious Housing and Hidden Homelessness Among Refugees, Asylum Seekers, and Immigrants in the Toronto Metropolitan Area. CERIS Working Paper No. 87.

Pruegger, V.J., \& Tanasescou, A. (2007). Housing Issues of Immigrants and Refugees in Calgary. Calgary: Poverty Reduction Coalition, United Way of Calgary and Area and City of Calgary.

Raphael, D. (2004). Social Determinants of Health: Canadian Perspectives. Toronto: Canadian Scholars' Press.

Rauh, V.A., Landrigan, P.J., \& Claudio, L. (2008). "Housing and Health. Intersection of Poverty and Environmental Exposures." Annals of the New York Academy of Sciences, 1136, 276-288. 
Shapcott, M. (2004). Housing. In D. Raphael (ed.). Social Determinants of Health: Canadian Perspectives (pp.201-215). Toronto: Canadian Scholars Press Inc.

Shapcott, M. (2010, Summer). Precarious Housing in Canada. Toronto: Wellesley Institute.

Shaw, M. (2004). "Housing and Public Health". Annual Review of Public Health, 25, $397-418$.

Sherrell, K., D'Addario, S., \& Hiebert, D. (2007). "On the Outside Looking In: The Precarious Housing Situations of Successful Refugee Claimants in the GVRD." Refuge, 24(2), 64-75.

Solari, C.D., \&. Mare, R.D. (2012). "Housing Crowding Effects on Children's Wellbeing." Social Science Research, 41, 464-476.

Springer, J., Roswell, T., \& Lum, J. (2006). Pathways to Homelessness among Caribbean Youth Aged 15-25 in Toronto. Toronto: Joint Centre of Excellence for Research on Immigration and Settlement - Toronto, CERIS Working Paper No. 44.

Statistics Canada. (2005). Longitudinal Survey of Immigrants to Canada: A Portrait of Early Settlement Experiences. Catalogue no. 89-614-XIE. Ottawa: Statistics Canada.

Tanasescu, A., Classens, M., Turner, D., Richter-Salmons, S., Pruegger, V., \& Smart, A. (2009). Hidden in Plain Sight: Housing Challenges of Newcomers in Calgary. Calgary: Calgary Homeless Foundation and the United Way of Calgary and Area.

Teixeira, C. (2008). "Barriers and Outcomes in the Housing Searches of New Immigrants and Refugees: A Case Study of 'Black' Africans in Toronto's Rental Market." Journal of Housing and the Built Environment, 23(4), 253-276

Teixeira, C. (2009). "New Immigrant Settlement in a Mid-Sized City: A Case Study of Housing Barriers and Coping Strategies in Kelowna, British Columbia.” The Canadian Geographer, 53(3), 323-339.

Teixeira, C. (2010). Housing Immigrants and Newcomers in Central Okanagan, BC. Vancouver: Metropolis British Columbia, Working Paper Series, No. 10-03.

Terashima, M. (2005, March). Housing and Homelessness Research in the Halifax Regional Municipality (HRM). Halifax: Commissioned by the Halifax Regional Municipality, Planning and Development Services.

UNHCR. (n.d.). Refugees. Retrieved August 17, 2012 From http://www.unhcr.org/pages/49c3646c125.html 
Wachsmuth, D. (2008). Housing for Immigrants in Ontario's Medium-Sized Cities. CPRN Research Report. Canadian Policy Research Networks Inc. and Social Housing Services Corporation.

Weich, S., Blanchard, M., Prince, M., Burton, E., Erens, B, \& Sproston, K. (2002). "Mental Health and The Built Environment: Cross-Sectional Survey of Individual and Contextual Risk Factors for Depression." Journal of Psychiatry, 180(5), 428433.

World Health Organization. (1946). WHO definition of Health, Preamble to the Constitution of the World Health Organization as adopted by the International Health Conference, New York, 19-22 June 1946; signed on 22 July 1946 by the representatives of 61 States (Official Records of the World Health Organization, no. 2, p. 100) and entered into force on 7 April 1948.

WHO. (2011). Health in the Green Economy: Health Co-Benefits of Climate Change Mitigation - Housing Sector. Geneva Switzerland: World Health Organization.

Xavier, B. (2007). "Inadequate Housing and Health: An Overview”. International Journal of Environment and Pollution, 30(3/4), 411-429.

Zine, J. (2009). "Living on the Ragged Edges: Latin Americans and Muslims and the Experience of Homelessness in Toronto." Chapter 5.1 in Hulchanski, J.D. et al., (editors). Finding Home: Policy Options for Addressing Homelessness in Canada. Toronto: Cities Centre, University of Toronto. 